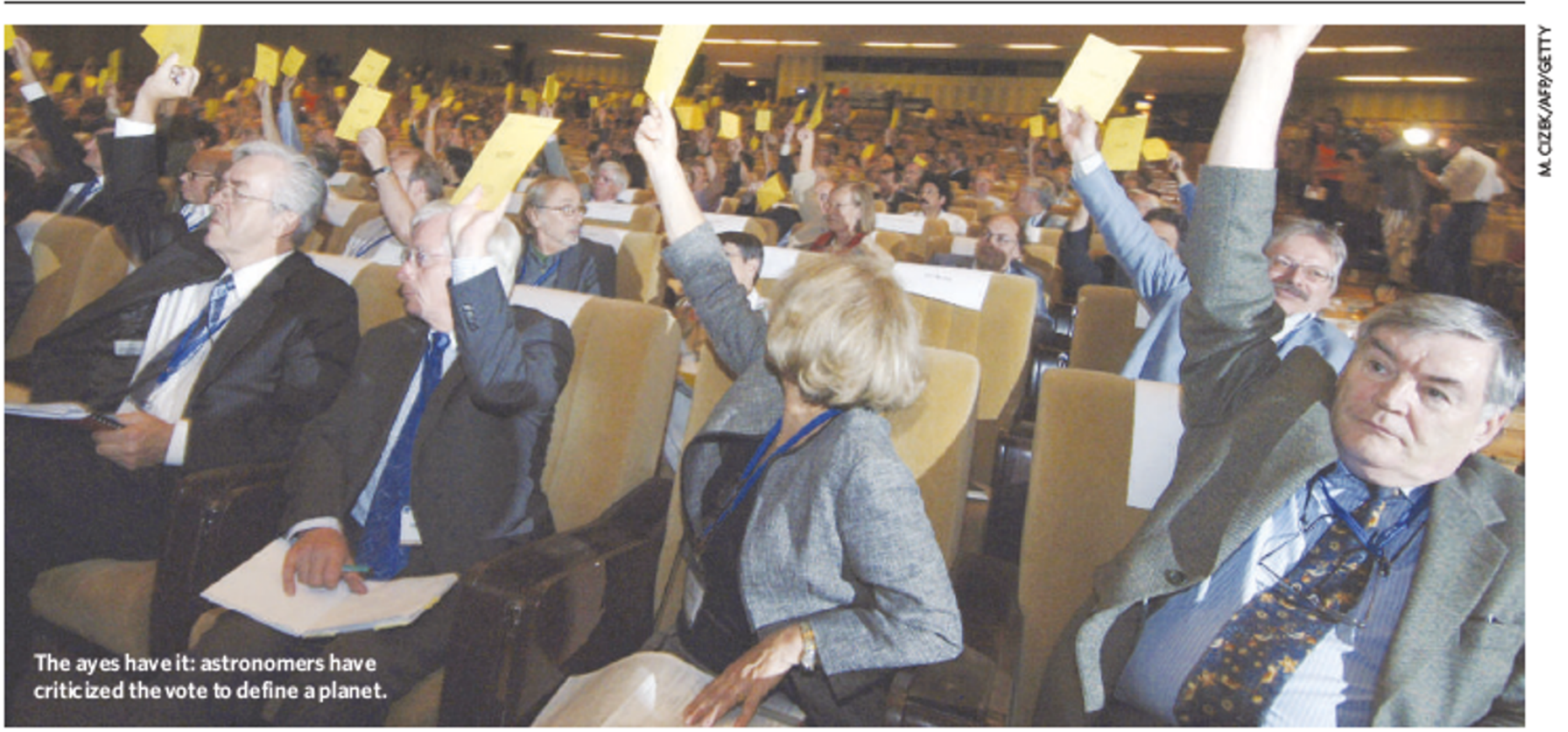

\title{
Pluto: the backlash begins
}

The future of the Solar System - or at least that of some of its nomenclature - may be thrown into turmoil by scientists who are calling for a boycott of a new definition of a planet.

On 24 August, delegates at the general assembly of the International Astronomical Union (IAU) in Prague voted to define the planets of the Solar System by three criteria. To deserve planet status, the assembly agreed, a chunk of rock or ball of gas must be big enough for its gravity to have made it round, must orbit the Sun but not be a satellite of another planet, and must have cleared other bits of debris from its orbit. Round objects, including Pluto, that failed on the final count became not planets but 'dwarf planets'.

The definition originally proposed on 16 August by the IAU would have had just two criteria - roundness and not being a moon. This was rejected by members at the meeting where the three-part definition was voted on as the final word on the subject. But many IAU members were not in Prague for the vote, and some are furious at the outcome.

"I am just disgusted by the way the IAU, which is meant to represent the best in science, handled this matter," says Alan Stern, a planetary scientist at the Southwest Research Institute in Boulder, Colorado. As principal

investigator for NASA's New Horizons mission to Pluto, he has a particular interest in its status. But he says the issue is not really Pluto's status so much as the idea of putting objects in orbital contexts. "We do not classify objects in astronomy by what they are near," he says. "We classify them by their properties."

The day after the new definition was unveiled, Stern was among a dozen scientists

"We do not classify objects in astronomy what they are near, we classify them by their properties."

-Alan Stern 200 people had added their names to the petition as Nature went to press on Tuesday.

Stern thinks that requiring a planet to have 'cleared its orbit' rules out some of the Solar System's other eight planets. These include Neptune, the orbit of which is crossed by Pluto, and Jupiter, which shares its orbit round the Sun with the Trojan asteroids.

The 'clearing' criterion was introduced when astronomers who study the dynamics of the Solar System insisted that the definition should recognize their idea of what constitutes a planet - an object with a mass that dominates its orbital zone. Owen Gingerich, chair of the committee that proposed the 16 August resolution, thinks the IAU had no choice but to bend to the dynamicists' demands. "They may not have had a majority for anything positive, but they could rouse a strong negative majority simply because there are so many little fiefdoms, he explains.

"The dynamics part of the definition is a rather complex one," says Ron Ekers, past IAU president. Couching the idea in terms of a planet 'clearing its orbit' was intended to make the issue easier for the public to understand. But it may well end up confusing matters.

Some organizations have already said they will accept the LAU's new definition. Encyclopaedia Britannica, for example, issued a statement saying that some of its articles on Pluto and the Solar System were updated online the same day the IAU's pronouncement was made. According to a spokesperson, later revisions may reflect any uncertainty, but ${ }^{\alpha}$ the vote by the IAU is considered binding - until the next vote, whether it's next year or next century". NASA, too, promised to abide by the definition, adding that it will "continue pursuing exploration of the most scientifically interesting objects in the solar system, regardless of how they are categorized".

Others are waiting to see how strong the counter-movement becomes. A black ribbon was tied around the Pluto panel at the Smithsonian Institution's National Air and Space Museum in Washington DC when the IAU's verdict was announced, says curator Andrew Johnston. But 
it has since been removed. "We're going to let things calm down for at least a few weeks before

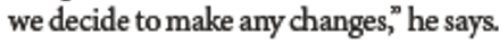

One thing that particularly irks critics is the way the decision was made. The IAU has nearly 9,000 members, but only 2,500 people attended the Prague meeting and only a fewhundred were present for the vote. The IAU should have used the Internet to gauge wider opinion, and then allowed electronic voting, according to those who oppose the definition.

"The IAU seems to be rooted in the preInternet age," says Mark Sykes, director of the Planetary Science Institute in Tucson, Arizona, who instigated the petition. "The rules of the IAU say that resolutions are passed by those present and voting," says Catherine Cesarsky, director of the European Southern Observatory and newly elected president of the IAU.

Sykes admits that a "better definition" might be hard to come by, but is still pressing for the current one to be scrapped. He thinks the IAU would be better off without any definition at all rather than the one they have chosen. "If they can determine that this process was flawed and nullify it, then I think that would be in their best interests, he says.

"If enough people are completely unhappy, we could go through the process again," says Ekers. But a new resolution would have to wait for the next general assemblyin 2009 in Rio de Janeiro. The IAU may issue a clarifying statement in the next week or two, but is hesitating to do so now. "Perhaps we need to make our next statement when things are a little less emotional," says Ekers.

Jenny Hogan

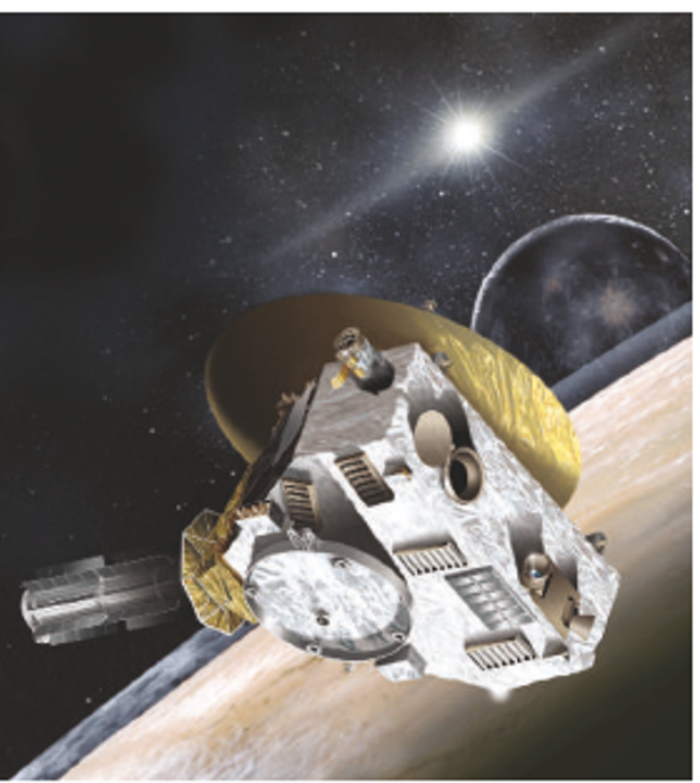

NASA's NewHorizons probe should reach Pluto in 2015, regardless of whether it is still a planet.

\title{
Diary of a planet's demise
}

\author{
While attending the International Astronomical Union's meeting in \\ Prague, Jenny Hogan kept the world up to date on the Pluto debate \\ through our newsblog. Edited excerpts:
}

\section{Monday 21 August}

The proposal to define a planet as anything round that isn't a moon, and thus increase the tally in our Solar System to 12, is scheduled for discussion at lunchtime tomorrow. But many astronomers have already conveyed their objections to the executive committee of the International Astronomical Union (IAU) by e-mail — and some are supporting a second, rival definition.

This alternative definition argues that a planet, as well as being round, must also be «by far the largest object in its local population". This definition knocks Pluto off its planetary pedestal (although it offers it concessionary 'dwarf planet' status), and destroys the chances of promotion for Ceres, queen of the asteroid belt.

Of the 100 people in the closed meeting last Friday where the alternative definition was floated, a show of hands showed about 50 for it and only 20 for the IAU's suggestion.

23:00 My dinner companions tonight include some (very tired) members of the Planet Definition Committee. They say they have received hundreds of e-mails over the past few days from geologists complaining about the proposal in the original definition to use 'pluton' to mean an object in the same class as Pluto. Pluton is a term of long-standing and wide use in geology, where it refers to an intrusion of igneous rock.

Another problem has emerged in translation. The French name for Pluto is - you've guessed it - Pluton. The definition committee thought this linguistic borrowing would give the pluton label special appeal for French-speaking astronomers, but apparently some of them object.

All this leads to speculation that tomorrow's revised definition, whatever other changes it contains, will include a replacement word for 'pluton'

\section{Tuesday 22 August}

15:00 For people who often tell journalists that defining a planet is a meaningless labelling exercise, astronomers actually seem to care a great deal. The open discussion on what makes a planet stopped just short of fisticuffs.

The official resolution has been divided into three parts, each of which will be voted on separately on Thursday at the closing ceremony. These cover the requirement of roundness, the distinction between a binary planet

\section{Dwarf planet in quotes}

"I'mhere I'm asphere.

Get used to it."

Pluto itself, talking to Gady Epstein of the Baltimare Sun about its recent demotion.

\section{"Idon't know about the public, but.... the as trologers will beupset." \\ PatrickMoore, astronomer and veteran presenter of the BBC's The Sky at Night.}

\section{“Pleasedon't turn Pluto into ad warf planet because that makes me sad. I'll miss Pluto a lot." \\ Daniel Dauber, aged six, on Nature's Newsblog,}

"This is as if botanists had found something between trees and bushes and invented the word 'animal' to describe it."

Allen Glazner of the University of North Carolina, Chapel Hill, on the proposal to call dwarf planets 'plutons' - a term that geologists have long used to describe certain bodies of rock.

"Since the term is not in
the Microsoft Word or
Word Perfect spellcheckers,
we thought it was not that
common."
Owen Gingerich, chairman
of the Planet Definition
Committee, which proposed
the use of thetermpluton.

"The comments were intelligent, but they came with apassion that makes me thinkthis debate has a non-intelligent dimension." Paul Murdin, Cambridge astronomer, at the annual meeting of the International Astronomical Union.

"It's over, it's done." Richard Binzel, an astronomer at the Massachusetts Institute of Technology and member of the Planet Definition Committee, on the Prague vote.

Sources: Baltimore Sun, Guardian, Nature, news@nature. 